\title{
Apunte sobre la profundidad y duración de la crisis financiera 2008
}

\author{
Joan Hortalà i Arau \\ Catedrático de Teoría Económica (U. B.) \\ y Presidente de la Bolsa de Barcelona
}

\section{INTRODUCCIÓN}

A principios de 2007, la mayoría de expertos estimaban que el ciclo bursátil «marcaba techo». Principalmente, por el largo período de expansión (desde principios de los 90 en EUA y desde mediados de la misma década en España) y, más concretamente, por la repercusión de la crisis inmobiliaria en el ciclo real y consecuente y progresiva pérdida de confianza. Las previsiones no incluían desajustes particularmente relevantes en los mercados financieros. Sin embargo, la crisis se ha focalizado en este ámbito y además con tal intensidad que se insinúa reformar el sistema económico vigente e incluso refundarlo (?)... El Bloomberg Financial Conditions Index (desviación estándar) muestra, comparativamente con otros acontecimientos significativos, la profundidad extrema de la caída bursátil del mes de octubre de 2008.

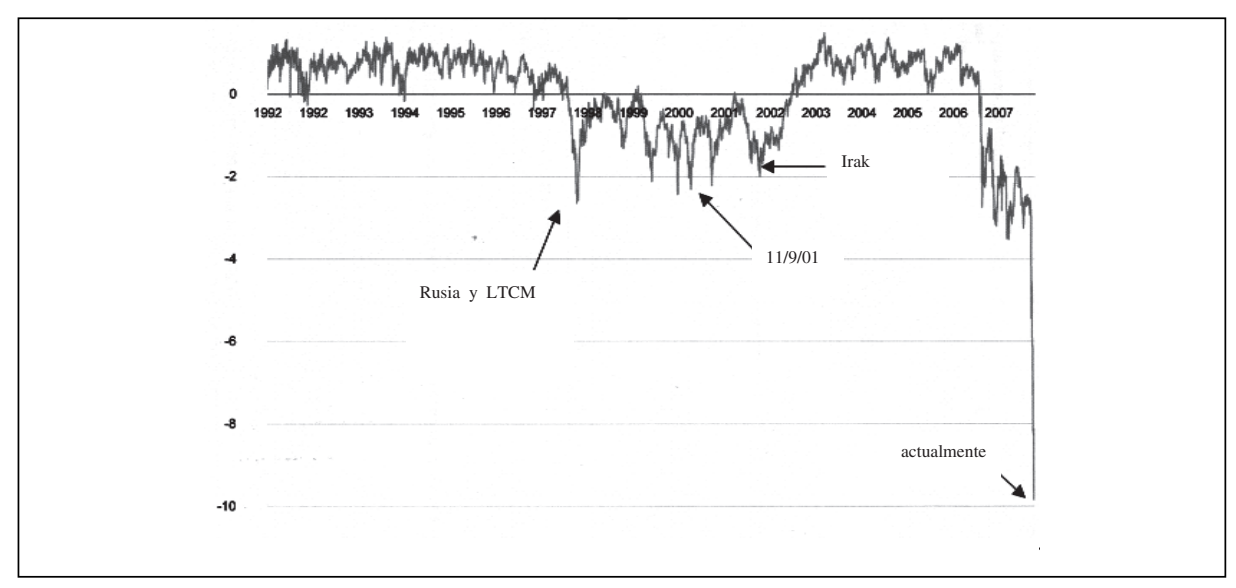


Como siempre ocurre en economía, todo tiene su lógica a posteriori. Una expansión significativa del crédito, por abundante liquidez y tipos de interés bajos, al socaire de una fase cíclica expansiva de larga duración y un sector-impulso (construccióninmobiliario) en crecimiento continuado. El crédito se centra básicamente en el de tipo inmobiliario y en el relativo a la financiación de nuevos productos financieros. Todo ello en un contexto de minimización del riesgo y sin regulación específica para esos productos tan novedosos como sofisticados.

Al entrar al fin en crisis el sector-impulso, surge de entrada el fenómeno de la insolvencia, tanto mayor cuanto peor es la naturaleza de los activos garantes del crédito otorgado. El desajuste sectorial repercute en el sistema financiero y la magnitud de tal repercusión condiciona el alcance del problema.

La irrupción de las hipotecas subprime precipita la crisis. Al principio, se quiso creer que sólo afectaba a la economía americana. Al poco tiempo, la certeza de la difusión urbi et orbe de «activos nocivos» engorda el impacto inicial y su propagación, al conjunto de los mercados, pone de relieve una importante pérdida de solvencia en el sector de la banca comercial y, secuencialmente, el hundimiento generalizado de los bancos de inversión, titulares y difusores de los activos de alto riesgo.

Ante la dimensión de la catástrofe y la obvia y contundente repercusión sobre el ciclo real, se arbitran diferentes medidas de intervención por parte de las administraciones públicas con la finalidad de proveer solvencia y retornar liquidez al sistema. La bolsa acoge los diferentes episodios en una trayectoria bajista de intensidad creciente y con registros de pánico a comienzos del mes de octubre.

\section{BURBUJA INMOBILIARIA E HIPOTECAS SUBPRIME}

Este crash bursátil responde de manera muy significativa al estallido de la burbuja inmobiliaria y las consecuencias de la misma sobre el sistema financiero a través de la popularización, especialmente en EUA, de las hipotecas de alto riesgo.

En realidad, en el país americano la expansión inmobiliaria comenzó a raíz de la crisis tecnológica de principios del siglo XXI, cuando precisamente, después de un largo período de prosperidad en las bolsas, las cotizaciones se desplomaron y los capitales, tanto los relativos a inversión como los institucionales, huyeron hacia los bienes inmuebles. Huída ésta abonada por la consolidación de una política monetaria de bajos tipos de interés, iniciada a principios de los años 90 y reforzada después de los atentados del 11 de septiembre de 2001, con el objetivo de reactivar el consumo y la producción a través del crédito. 
La posibilidad de adquisiciones apalancadas empujó la actividad constructora, alcanzando sus máximos alrededor de 2004, cuando la FED, para controlar la inflación acelerada por estas circunstancias, comenzó a subir el tipo de interés del 1\%, al 5,25\% en que se situó a finales del año 2006. El crecimiento del precio de la vivienda, que había sido espectacular entre 2001 y 2005, sufrió de repente un descenso importante. Inicialmente se registraron ejecuciones hipotecarias debidas al impago de la deuda e incluso quebraron diferentes entidades hipotecarias.

En este marco, la crisis inmobiliaria llegó a la bolsa. Pero lo hizo con efectos directos sobre el sector afectado. De hecho, el índice bursátil de la construcción (U.S.Home Construction Index) cayó un $40 \%$ el año 2006. Sin embargo, el resto de la actividad bursátil continuó con su trayectoria ascendente.

En España la evolución fue diferente, al margen que al final también estallase la burbuja inmobiliaria. El ciclo alcista se inicia a mediados de 1998, un poco antes que en EUA y su duración algo más larga, hasta 2007. En todo este período, los precios de la construcción superaban con creces la evolución del IPC. En promedio los precios de la vivienda subieron por encima del $10 \%$ anual, llegando en algunos años cerca del $30 \%$.

La demanda parecía no tener límite y un tal crecimiento empujaba la especulación, tanto por la evolución de los precios como y particularmente por la amplitud y laxitud en la recalificación de suelos. Circunstancias propias presionaban además la construcción de nuevas viviendas. Primero, el aumento de la inmigración (de 1998 a 2006 pasó del 1,6\% al 9,93\%, siendo la tercera tasa más alta del mundo). Segundo, la demanda residencial turística (1.500.000 de personas ya en 2003). Tercero, la segunda residencia (una por cada diez personas). Cuarto, el crecimiento del número de divorcios (un incremento del $79 \%$ anual entre 1993 y 2003). Y, quinto, los bajos tipos de interés y las facilidades crediticias, aspectos éstos que, por supuesto, a diferencia de los anteriores no eran privativos del caso español.

En este marco, entre 1999 y 2001 se iniciaron más de 500.000 viviendas al año y en el año 2006 se habían registrado 800.000. Al año siguiente, las licencias bajaron y la estimación para 2008 los sitúa por debajo de los 150.000. El ciclo había tocado techo y la burbuja estalló en 2007. Por descontado que, al igual que en América, también el estallido llegó a la bolsa. A finales de este verano, el índice que más bajaba del conjunto (un 59,21\%) no era otro que el BCN-5 Inmobiliarias.

La repercusión de la crisis inmobiliaria sobre los mercados financieros pone de relieve otra crisis: la de las hipotecas de alto riesgo o subprime. Éstas constituyen un tipo especial de hipoteca utilizado preferentemente para la adquisición de vivienda por 
parte de clientes con escasa solvencia, diferenciándose así de las hipotecas «corrientes» o prime. Su tipo de interés es más elevado que el de los préstamos personales y las comisiones bancarias más gravosas. De entrada, la FED impuso un límite a la concesión de este tipo de préstamos, si bien en los tiempos de euforia se relajaron los estándares de supervisión.

La deuda inherente a la hipoteca fue objeto de venta y transacción económica a través del procedimiento de la titulización. De esta forma, las hipotecas subprime se retiraban del activo del balance de la entidad concesionaria al transferirse a fondos de inversión o a planes de pensiones. Gradualmente, el alto riesgo de este producto financiero fue soslayándose, al extremo que en los momentos de auge, en los cuales los capitales financieros circulan con rapidez y cambian de mano con frecuencia en un marco sofisticado y automatizado, los titulares finales desconocían el verdadero alcance del riesgo asumido (sin que de hecho les importara, justamente por el clima de euforia coyuntural).

Sin embargo, cuando el precio del dinero empieza a aumentar y las cuotas se encarecen, surge la morosidad y las ejecuciones hipotecarias. Y eso, al suceder en un escenario en que de repente se pone de relieve que las entidades bancarias y los fondos de inversión y de pensiones están en posesión de activos hipotecarios de alto riesgo, deteriora la confianza, restringe el crédito (credit crunch), aumenta la volatilidad bursátil y presiona los mercados a la baja, que se generaliza por las implicaciones propias de la globalización financiera.

\section{ANDAMIAJE INSTITUCIONAL}

Este lío monumental, ceñido en principio al sector financiero, tiene en buena medida su origen cuando la Administración Clinton presionó a las entidades de crédito para facilitar hipotecas a grupos étnicos y raciales y, en general, a peticionarios con escasos recursos. La medida, de supuesta intencionalidad social, no tuvo particular rechazo porque la fase de prosperidad que en aquel entonces caracterizaba la situación económica predisponía a minimizar el riesgo, al margen de altos registros en los niveles de liquidez. Precisamente por una tal bonanza coyuntural, la elevada probabilidad de impago de las hipotecas concedidas (que con el tiempo alguien ha denominado «ninjas»: no income, no job, no assets) tenía como compensación potencial el alza continuada del precio de las viviendas hipotecadas, en el supuesto que tuviera que ejecutarse la garantía. 
En este punto es importante tener en cuenta que la mortgage americana no se corresponde en derecho a la hipoteca que se concede de acuerdo con el régimen español. Mientras en EUA es una obligación real, en España es una obligación personal con garantía real. Por tanto, en EUA, en caso de insolvencia, no se responde con todo el patrimonio, sino tan solo con el bien hipotecado.

La presión de la Administración americana abarcaba a todo el sistema crediticio, con particular énfasis a aquellas entidades paraestatales como la Federal National Mortgage Association Housing (Fannie Mae) y la Federal Home Loan Mortgage Corporation (Freddie Mac). La primera se creó en 1938 y la segunda en 1970. Ambas tenían como objetivo social prioritario el crédito hipotecario sobre viviendas para familias de rentas bajas y medias. Las dos cotizaban en Wall Street, sin registros obligatorios en la SEC, gozando de exención tributaria tanto a nivel estatal como local. En 1992 se creó la Office of Federal Hausing Enterprise Oversight (Ofheo) para consolidar su operativa y su expansión, ampliando al trato especial que ya recibían de U.S.Treasury en forma de líneas de crédito. De hecho, Fannie Mae y Freddie Mac canalizaban más del $50 \%$ del crédito sobre vivienda.

Cuando a principios de agosto de 2007 American Home Mortgage, el décimo banco hipotecario de EUA, suspende pagos, aflora de repente el conflicto financiero con todo el entramado de conexiones que, con la denominación subprime, desvelará una crisis de gran profundidad y mayor alcance a partir de la aparición de niveles inusitados de insolvencia y la formación de un clima de gran desconfianza que repercute en la liquidez y en el crédito. Sin embargo, en esta época (y hasta septiembre de 2008 en que resultan intervenidas) Fannie Mae y Freddie Mac mantienen aún su estándar de referencia, porque las implicaciones del desajuste derivan a marcha forzada hacia los bancos de inversión en la medida que se va «descubriendo» una extensa operativa basada en nuevos productos financieros, muchos de los cuales constituirán el grueso de los «activos tóxicos».

\section{LOS NUEVOS PRODUCTOS FINANCIEROS}

Estos nuevos productos financieros se sustentan inicialmente en la titulización de activos hipotecarios y luego en la combinación de estructurados realizados sobre los mismos. El engranaje es el siguiente:

Primero, la banca comercial otorga una hipoteca a una persona de escasa solvencia, que le ha sido presentada por un broker inmobiliario el cual percibe la comisión 
correspondiente. Segundo, el banco, a pesar de gozar de buena liquidez, tiene la certeza que podrá transferir la hipoteca al sistema con un determinado margen y, en el peor de los casos, podrá recuperar el activo hipotecado si después de los dos años de carencia no se procede a su amortización, en el bien entendido que no incurrirá en pérdidas habida cuenta el alza permanente de los precios en el sector inmobiliario. Tercero, en la medida que el banco comercial acumula hipotecas de esta naturaleza, las transfiere a su vez a un banco de inversión. Cuarto, el banco de inversión agrupa el conjunto de hipotecas así adquiridas, creando un nuevo producto financiero denominado SPV (Special Poorpose Vehicle). De ahí deriva todo lo demás, ya que de los SPV se forman o MBS (Mortgage Backet Securities) o CDO (Collateralized Debt Obligation).

MBS es una emisión de obligaciones sobre hipotecas. El banco de inversión traslada el riesgo hipotecario de quiebra al mercado. Se compromete, sin embargo, a recomprar un porcentaje de la emisión si se impagaba un número determinado de hipotecas. El producto tiene particular aceptación para inversiones a largo plazo y las entidades preponderantes en este marco no son sino Freddie Mac y Fannie Mae.

CDO se basa también en la emisión de obligaciones (largo plazo) y bonos (corto y medio plazo) sobre hipotecas y, en este caso, transfiriendo todo el riesgo al mercado. Se ofrecen principalmente a instituciones de inversión colectiva (fondos de renta fija, monetarios y hedge funds). Se presentan con diferentes niveles de riesgo. Los más seguros tienen rating $\mathrm{AAA}$, los de mediano riesgo, rating $\mathrm{BBB}$ y los más arriesgados son los llamados «equities». Además, para asegurar a los potenciales compradores el posible perjuicio de morosidad en algún pago de la amortización de las hipotecas incluidas en el paquete, se suscribe un seguro relativo a tales quebrantos mediante un instrumento denominado CDS (Credit Default Swaps). La aseguradora AIG fue una de las más activas en la formalización de CDS.

Todos estos nuevos productos, que en definitiva son activos de renta fija, meritan un rendimiento muy superior al del mercado, obviamente con riesgo escalonado según la naturaleza del paquete. El éxito es espectacular, al extremo que en una alocada espiral vendedora, se crea un nuevo instrumento: el Synthetic CDO. Este producto se basa igualmente en la emisión de bonos con seguro CDS y una referencia a los CDO iniciales, los cuales estaban a su vez referenciados a hipotecas. El CDO sintético se convierte en una inversión de «moda» entre los expertos del mercado institucional y el apalancamiento para esta finalidad es, a su vez, práctica habitual entre el público inversor. De hecho, el volumen de CDO sintético llegó a superar el 70\% del volumen total de CDO emitidos. 
Cuando estalla la crisis, dos cuestiones sobresalen entre otras muchas. Primera, el conocimiento exacto de los activos tóxicos emitidos y particularmente su distribución geográfica. Sin embargo, era evidente que, por la avidez con que fueron aceptados estos productos, la globalización los había extendido a diferentes países, con lo cual el problema es «global» y no exclusivamente americano. A este respecto, en marzo de 2007, el FMI había alertado que en EUA existían alrededor de 4,2 billones de euros en bonos ligados a hipotecas de alto riesgo de los cuales alrededor de 700.000 millones de euros pertenecían ya un año antes a inversores no estadounidenses. Poco más tarde, en el mes de agosto, se supo que los dos principales bancos chinos (Comercial Bank of China y Bank of China) tenían más de 8.000 millones de euros en inversión hipotecaria subprime.

La segunda cuestión a tener en cuenta tiene que ver con el hecho de que no era posible establecer una valoración correcta de los activos subyacentes y, por lo tanto, calcular su valor liquidativo. Esto motivó, de una parte, que diferentes entidades europeas suspendieran (temporalmente) fondos de inversión por falta de liquidez (el caso de BNP-Paribas, fue el más espectacular y también, en menor medida, el del Deutsche Bank). Por otra parte, en particular a mediados de agosto, esta constatación generalizó e incluso aceleró que los bancos centrales de la zona euro y de EUA inyectaran masivamente liquidez para atenuar las tensiones del mercado interbancario.

Los nuevos productos financieros y sus problemas se extendieron por doquier con mayores o menores matices. En España, si bien en un primer momento se rumoreó la existencia de activos tóxicos (sin demasiado fundamento se citaron $B B V A$ y los bancos Popular y Sabadell), el problema fue diferente. No se trató ni se trata, ahora mismo, de un peligro de insolvencia sino de una gran carestía de liquidez y consecuente restricción crediticia. Y es que los «paquetes» hipotecarios españoles, en forma de cédulas hipotecarias, tenían buena aceptación, sobre todo en el mercado alemán, debido a que la transmisión no incluía el riesgo hipotecario incorporado, al garantizar las entidades españolas el buen fin de los préstamos incorporados.

En este marco, la crisis financiera asociada a hipotecas subprime tuvo poco alcance, si es que alguno, en el mercado español. La parte conflictiva, en todo caso, es el cierre de las habituales fuentes de aprovisionamiento financiero y la circunstancia, nada desdeñable, que mientras las cédulas hipotecarias tienen vencimiento a uno, dos y tres años, el plazo de las hipotecas que las soportan supera los veinte. Este punto es crucial para entender tanto la gravosa e importante restricción de crédito, como la mutua desconfianza entre entidades financieras y consecuente parón del mercado interbancario. 


\section{PerCANCES Y EVOLUCión BURSÁTIL}

En la jornada del 11 de octubre de 2007 el Dow Jones registraba altos históricos $(14.198,10)$ y a las pocas semanas, el 9 de noviembre, el alto histórico se lo apuntó el Íbex-35 (16.040,40).

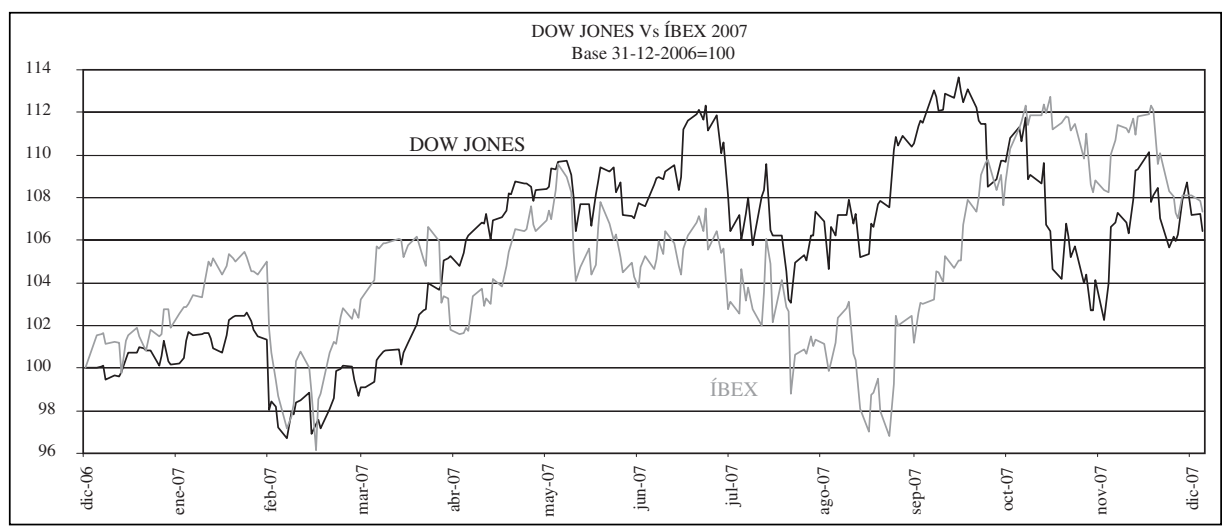

El año 2007 fue un año alcista en su conjunto (Íbex $+7,32 \%$ y Dow $+6,43 \%$ ), siendo además el quinto año consecutivo de ganancias bursátiles. En realidad, los índices de cierre fueron sólo ligeramente inferiores a los registrados en los respectivos puntos máximos. Con todo, en el segundo semestre ya se observaron movimientos bajistas que, si bien luego se compensarían, revelaban evidencias sobre que el largo ciclo alcista había tocado techo.

De hecho, después del aviso que dio en el mes de julio Bear Stearns, al anunciar la quiebra de dos de sus más importantes fondos de inversión, los acontecimientos de los primeros días de agosto confirmaban que el desajuste financiero americano se internacionaliza. Al poco tiempo, en Francia la BNP tiene problemas; en Alemania el Deutsche Bank anuncia pérdidas importantes en uno de sus fondos vinculado a la financiación inmobiliaria y el banco regional público Sachsen L.B. ha de ser rescatado por un grupo de cajas de ahorro; en Australia la entidad hipotecaria Rams Home Loans se desploma en bolsa; en España la Banca March congela un fondo de inversión (Parvest Dynamic $A B S$ ); en Suiza $U B S$ anuncia números rojos... y todo ello constatando que 90 entidades financieras americanas ya estaban afectadas por la crisis, que American Home Mortgage había suspendido pagos, que el primer banco hipotecario (Countrywide) atravesaba tiempos difíciles cercanos a la bancarrota, que HSBC y Citibank se ven 
obligados a absorber en balance casi 100.000 millones de dólares en activos dañados y que el Presidente de Merrill Lynch y el de Citigroup habían renunciado a su cargo.

En este marco, los mercados bursátiles incorporan gran volatilidad y el interbancario, ante una carencia alarmante de liquidez, sitúa el euríbor a máximos en relación a los tipos oficiales contenidos por el BCE. Ello no obstante, la adopción de medidas de política económica, en particular durante el cuarto trimestre del año 2007 (España constituyó una excepción) relativizaba el alcance inmediato del conflicto.

De septiembre a diciembre, la $F E D$ recortó tres veces 25 puntos básicos el tipo de interés, situándolo del 5\% al 4,25\%. Y, conjuntamente con el BCE y el Banco de Inglaterra, inyecta dinero al sistema. Medidas todas éstas que preludian las adoptadas, a mediados de diciembre, por los bancos centrales de EUA, Inglaterra, Europa, Canadá y Japón en una acción concertada para mejorar los coeficientes de solvencia e impulsar la liquidez ante la repentina y elevada restricción del crédito.

La conciencia generalizada de que el ciclo había llegado a su fin y que, por lo tanto, la evolución bursátil subsiguiente iba a ser complicada se desprendía de la inmensa mayoría de los pronósticos para el ejercicio 2008.

Durante el primer trimestre de este año, el Dow Jones cayó un 7,55\%. En cambio el Íbex acusó un descenso del 12,6\%. La diferencia era sintomática y, sin embargo, las autoridades económicas españolas continuaban opinando que el problema sólo se localizaba en EUA. De hecho, no se quería reconocer la posibilidad de una crisis importante, más allá del desajuste inmobiliario. En los Estados Unidos de América, en cambio, la $F E D$ volvió a rebajar el tipo de interés. Dos veces en el mes de enero y otra a mitad de marzo. En total 200 puntos básicos, con lo cual el tipo se situaba al 2,25\%.

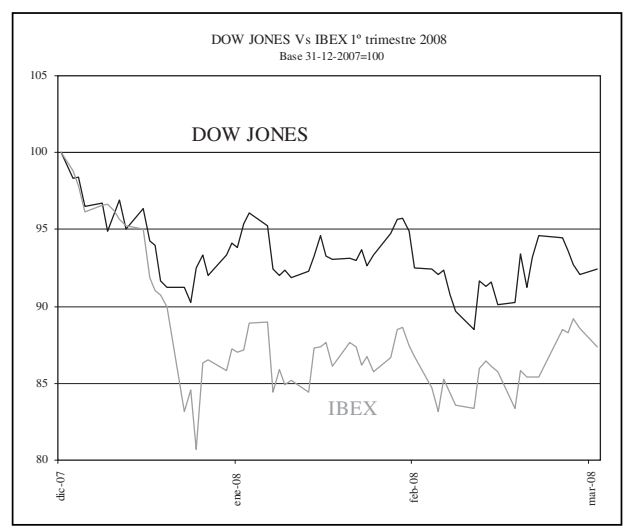


A lo largo de este primer trimestre del año 2008, la consolidación de la crisis financiera iniciada en el segundo semestre del año anterior iba tomando cuerpo a marchas forzadas, a excepción de los últimos días del mes de enero en que resultados empresariales positivos empujan al alza al conjunto de las bolsas mundiales. La alegría fue fugaz. Porque a las noticias relativas al error de un broker de Société Générale, las provisiones de Citigroup y la compra de Countrywide (banco especializado en hipotecas de alto riesgo) por el Bank of America, se añadieron a reglón seguido el desplome del francés Banque Natixis, la reducción de beneficios de Crédit Suisse por tenencia de activos subprime, la nacionalización por parte del gobierno británico del banco Northern Rock (17.2.08) y el desplome bursátil hasta el 90\% de las acciones de la gestora americana Bear Stearns, lo cual motivaría la posterior compra a dos dólares por acción que realizará J.P. Morgan (16.3.08). Más adelante se nacionalizará el banco IndyMac. Además, los nuevos datos macroeconómicos americanos, a diferencia con los del trimestre anterior, anunciaban claramente una senda recesiva. También los datos económicos suministrados por las autoridades de la UE ponían de manifiesto que la crisis se estaba consolidando en el Viejo Continente.

Al empezar el segundo trimestre de 2008, se observan comparativamente descensos importantes en los volúmenes de contratación. Las bolsas continúan cayendo, el resultado trimestral arroja una caída del 7,44\% en el Dow Jones y de 9,22\% del Íbex. En términos anuales, $14,43 \%$ y $20,66 \%$ respectivamente.
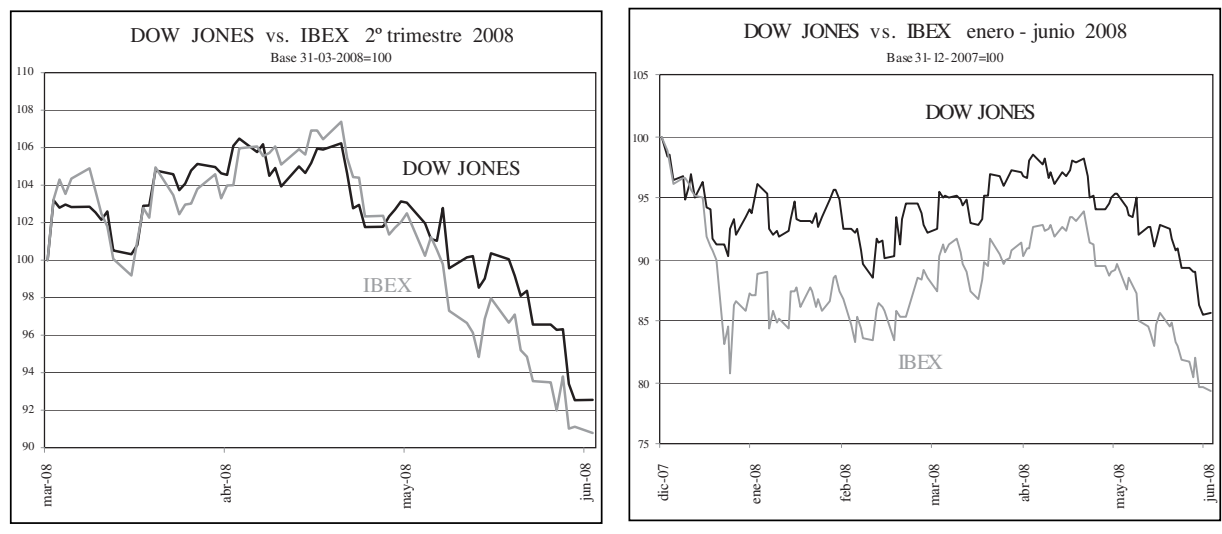

En este intervalo temporal sobresalieron más los descalabros bancarios que el alcance de las medidas económicas. De hecho la $F E D$ recortó un cuarto de punto a finales del mes de abril y mantuvo la tasa resultante del $2 \%$ en la reunión del mes de junio. Por su parte y pese a todo, el BCE mantiene el tipo de interés en el 4\%. En cambio, en 
el sector bancario se agravan las situaciones relativas, ya en un contexto globalizado. $U B S$, City Group, HSBC, Fortis y Credit Agricole anuncian pérdidas multimillonarias. Como colofón dimite el Consejero Delgado de $A I G$, la mayor aseguradora del mundo y se anuncian problemas en Fortis. Con todo, los mercados mantuvieron a lo largo de esos tres meses una tónica relativamente estable, oscilando el Íbex en una franja entre 12.500 y 14.000 y el Dow Jones, más suave, entre 12.300 y 13.000 .

Al empezar el tercer trimestre, el Banco Santander compra Alliance \& Leicester. A mediados de julio el barril de petróleo Brent cierra a 144,49 dólares, tras el máximo de 147,50 , y el euríbor sube a 5,398\%. El panorama general continua inquietante y van sucediéndose los percances: caen los beneficios de BNP, de Société Générale, de HBOS, las acciones de Lehman Brothers pierden un $44 \%$ y una semana más tarde se declara en quiebra. Mientras tanto, el Bank of America compra Merill Lynch y Morgan Stanley negocia su fusión con Wachovia, como antesala para transformarse, conjuntamente con Goldman Sachs, de bancos de inversión a bancos comerciales.

En este escenario el gobierno americano interviene Fannie Mae y Freddie Mac, mediante un singular proceso de nacionalización. El BCE inyecta 95.000 millones de euros al sistema y diez bancos mundiales acuerdan un programa de préstamos de 70.000 millones de dólares para combatir la crisis financiera. Con todo, el $B C E$ mantiene el tipo de interés en el 4,25\%, después de haberlo subido un cuarto de punto el día 3 de julio. También la FED mantiene el tipo de interés en el $2 \%$, iniciándose el rescate de $A I G$.

Los mercados, obviamente, acusan cada vez más el impacto de la crisis financiera y las cotizaciones descienden sin solución de continuidad. A finales de septiembre la situación se agrava y los gobiernos empiezan a actuar abiertamente. El 18 de septiembre el gobierno americano estudia la concepción de un plan anticrisis para evitar nuevas
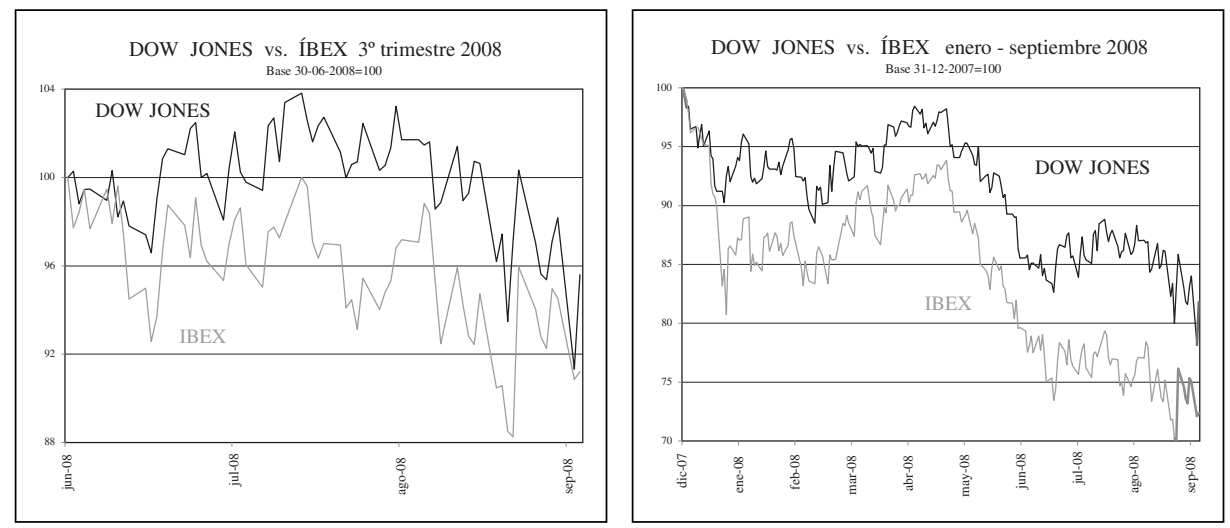
quiebras. Sorprendentemente, la bolsa española acoge el acontecimiento con una subida $(8,71 \%)$, tan notoria como fugaz. Wall Street, en cambio, no se alteró ni siquiera cuando la Casa Blanca anunció un plan de rescate de 700.000 millones de dólares. Pero reaccionó negativamente al día siguiente (29/9), cuando el Congreso rechaza el plan de salvamento, anotando un descenso del 6,98\%. En este alarmante panorama el Benelux se queda con el $49 \%$ de Fortis y el Banco Santander asume parte del Banco Bradford \& Binglei, después de la intervención del gobierno británico.

Durante este tercer trimestre el mercado español descendió un 8,79\% y el americano un $4,40 \%$, que sumados a los datos anteriores arrojan un descenso anual de $27,62 \%$ y $18,20 \%$, como indican las evoluciones de los gráficos anteriores.

La decisión del gobierno irlandés de garantizar la totalidad de depósitos bancarios convulsiona a las autoridades de otros países, que posteriormente harán lo propio modificando al alza las garantías tanto de depósitos bancarios como de participaciones en fondos de inversión. El clima de desconfianza es general y el cuarto trimestre, con estas iniciativas como punto de referencia, acoge desde el primer día de septiembre la asimetría entre los planteamientos americanos y los europeos, ya que mientras las autoridades de la UE rechazan en París crear un gran fondo común de ayuda a los bancos, el Senado americano, esta vez sí, aprueba con ciertos retoques el plan de salvamento presentado por el Secretario del Tesoro Paulson (1.10.08).

El impacto de todo ello en los mercados es nuevamente dispar. En la bolsa española esta iniciativa se acoge positivamente (el viernes día 3 de octubre el Íbex sube un 3,78\%). En la bolsa americana el Dow Jones baja un 1,50\%, lo cual fija el prólogo de lo que va a ser la segunda semana de octubre, una verdadera black week, a lo largo de la cual el Dow Jones desciende alrededor del $20 \%$ y el Íbex nada menos que un $25 \%$.

El lunes día 6 de octubre el $B C E$ mantiene el tipo de interés en el 4,25\%. Dos días más tarde lo bajará hasta el $3,75 \%$ en consonancia con el acuerdo que incluye a los bancos centrales de los países implicados en la crisis. Tales iniciativas responden al plan del gobierno británico de Gordon Brown que prevé una nacionalización parcial de todos los bancos.

El gobierno español, tiene que admitir la situación (7.10.08) y su Presidente anuncia la creación de un fondo de 50.000 millones de euros para la compra de activos financieros del sistema bancario. Nicolas Sarkozy y los 15 países del eurogrupo acuerdan un plan de acción para garantizar los préstamos bancarios y la posible recapitalización de los bancos. Por su parte, el gobierno estadounidense entra en el capital de los grandes bancos del país: Citi, J.P. Morgan, Bank of America, Wells Fargo, Goldmans...

Y todo ello en un contexto en que los datos macroeconómicos empeoran, los déficits comerciales aumentan e igualmente crece la tasa de paro, que en España llega 
al $11,3 \%$, cifra más alta desde 2004. En este marco, el mercado de futuros de Estados Unidos cierra momentáneamente y la FED baja el tipo de interés al 1\% (26.10.08). Previamente, el gobierno británico decreta el control de RBS, HBOS y Lloyd's; el gobierno holandés inyecta 10.000 millones de euros a $I N G$ y espectacularmente, el gobierno argentino nacionaliza el sistema privado de pensiones.
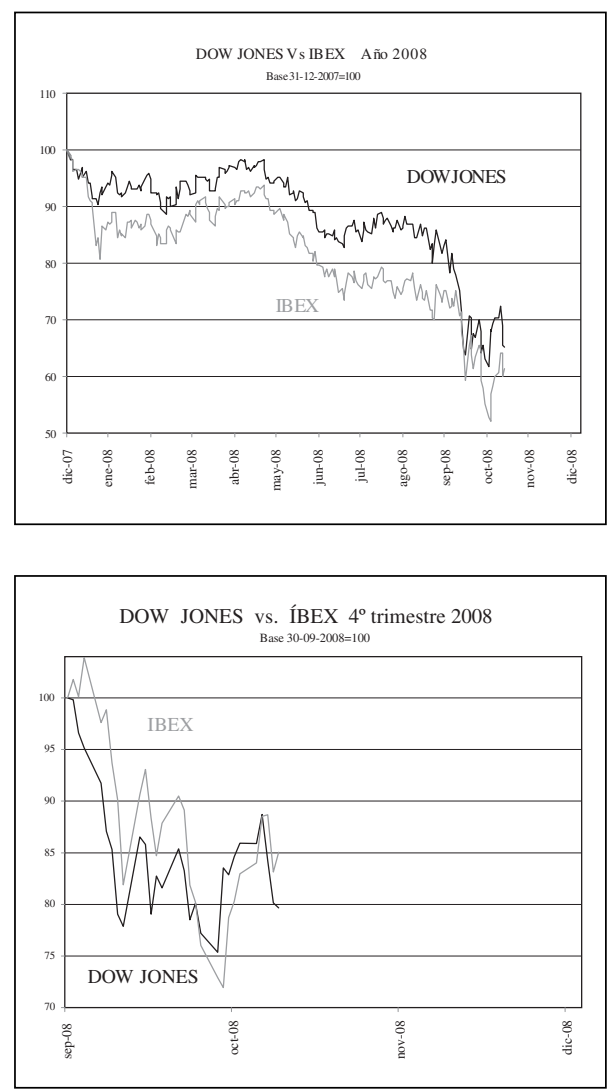

El 4 de noviembre Barack Obama gana las elecciones americanas. Pero la bolsa ya había descontado la esperada victoria: subió el día anterior y bajó estrepitosamente los días siguientes, primero un 5,05\% en Nueva York y luego un 6,27\% en el mercado español. A esta fecha, la bolsa española había bajado en el trimestre un $14,96 \%$ y en el total del año un 38,46\%. La de Nueva York, por su parte, un 20,34\% $\mathrm{y}$ un $34,84 \%$. 


\section{TRANSMISIÓN CÍCLICA}

El carácter adelantado del ciclo financiero sobre el ciclo real es, en términos generales, un hecho que goza de aceptación empírica. Diferentes teorías avalan esta interrelación, con énfasis particular sobre el alcance de factores psicológicos. El gráfico siguiente muestra, a título indicativo, la evolución de los incrementos del Índice General de la Bolsa de Barcelona y del PIB desde 1940 hasta la actualidad.

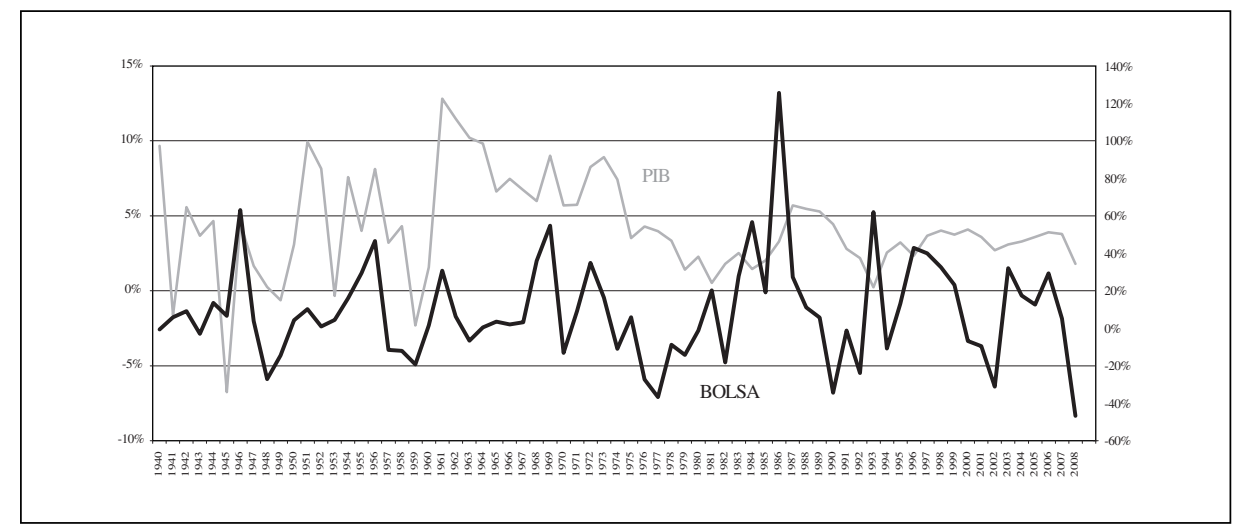

Se observa así que, efectivamente, el ciclo financiero anuncia el ciclo real. Sin embargo, con una cierta asimetría. Mientras el carácter de adelanto se manifiesta verosímilmente en las fases contractivas, no sucede lo mismo en las fases de recuperación. Las caídas bursátiles adelantan plausiblemente las disminuciones de los niveles de producción y ocupación. En cambio, en las fases de recuperación, no siempre ni con el mismo ritmo, la mejora bursátil predice el cambio de tendencia de la economía real.

Una explicación de esta asimetría puede residir en la prioridad que los gobiernos otorgan a restablecer la ocupación o a estabilizar los precios. En cada situación, las lecciones del pasado han sido importantes así como los avances experimentados por la nueva macroeconomía, en particular desde la síntesis neoclásica, después de la revolución keynesiana, hasta las últimas teorías sobre el ciclo real.

En cualquier caso, la política anticíclica juega un papel dispar según sea la fase del ciclo. En realidad, no es el mismo el peso relativo de la política monetaria o de la política fiscal. En la vorágine contractiva predomina la política monetaria, mientras que las medidas fiscales, independientemente de las actuaciones por el lado de la oferta, se combinan prioritariamente con otras de tipo monetario en los períodos de recuperación. Ya sea porque la 
política monetaria es de más rápida instrumentación en tanto que medida de choque, ya sea por las tesis favorables al presupuesto equilibrado incluso en coyunturas recesivas.

Este último argumento, de todas formas, es objeto de discusión tanto desde el punto de vista político-ideológico, ligado al dilema desregulación-intervencionismo, como desde el punto de vista de necesidad. Es decir, según la gravedad y alcance de cada situación coyuntural.

La inclinación relativa a favor de la política fiscal plantea en el fondo el dilema de a quién, vía incremento de la demanda agregada, corresponde reactivar la economía a corto plazo. La tendencia más liberal se inclina por el sector privado, a través de la reducción de impuestos; la socialdemócrata, por el sector público mediante el aumento del gasto. En uno y otro caso, el resultado es el mismo: mayor déficit presupuestario. Pero los instrumentos son diferentes. Unos defienden bajar los impuestos para que así sea el sector privado el motor de la recuperación y otros aumentar el gasto público para que tenga el protagonismo en esta fase cíclica el Estado. En todos los casos, el énfasis a favor de la política fiscal pondera la importancia cíclica del gasto agregado.

Sea la que sea la instrumentación de las medidas económicas, la transmisión cíclica se fundamenta en cada situación en circunstancias específicas. Es decir, dada la naturaleza de la crisis, una circunstancia, ya sea psicológica, monetaria o real, ejerce la función de factor de transmisión. En el panorama actual, el factor riesgo traslada los efectos de la burbuja inmobiliaria al sector financiero y el factor crédito transmite la crisis financiera al ciclo real.

Los desarrollos gráficos de los cuadros siguientes constatan esta transmisión. Efectivamente, la evolución del PIB responde a los descensos de las cotizaciones, teniendo en cuenta la interrelación de los indicadores bursátiles desde su punto máximo (Íbex, 8 de noviembre de 2007 y Dow Jones, 9 de octubre de 2007) y los registros de decrecimiento de la producción a partir del segundo semestre de 2007.
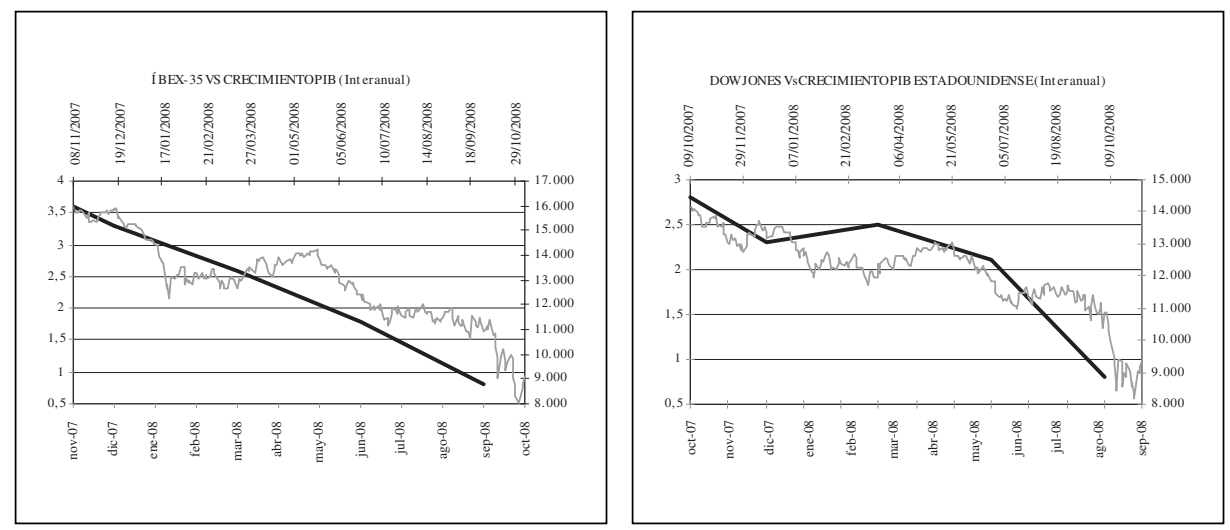
Las conjeturas sobre esta interrelación son varias y de alcance distinto. En términos generales y sin negar la certeza de la transmisión del ciclo financiero sobre el ciclo real, las repercusiones sobre los niveles de producción y ocupación son diferentes para la economía americana que para la economía española. Justamente por ello, las previsiones ponen de relieve que, si bien a medio plazo es obvia la disminución en la demanda de consumo y de inversión, en EUA la incidencia se centra mayormente en la producción mientras que en España el problema se localiza en la ocupación. Y ello, sin merma de las implicaciones sobre morosidad que también se prevén de mayor alcance para el caso español.

\section{REFERENTE HISTÓRICO}

El ciclo financiero condiciona la economía real. Y según sea la importancia de aquel, mayores serán las consecuencias sobre la evolución de los volúmenes de producción y ocupación. En este sentido, es útil «enmarcar» la profundidad y duración del crash bursátil de 2008.

El referente histórico ofrece para este empeño enseñanzas nada desdeñables tanto de tipo conceptual como operativamente. Los gráficos que siguen muestran la evolución bursátil en EUA y España (Bolsa de Barcelona).

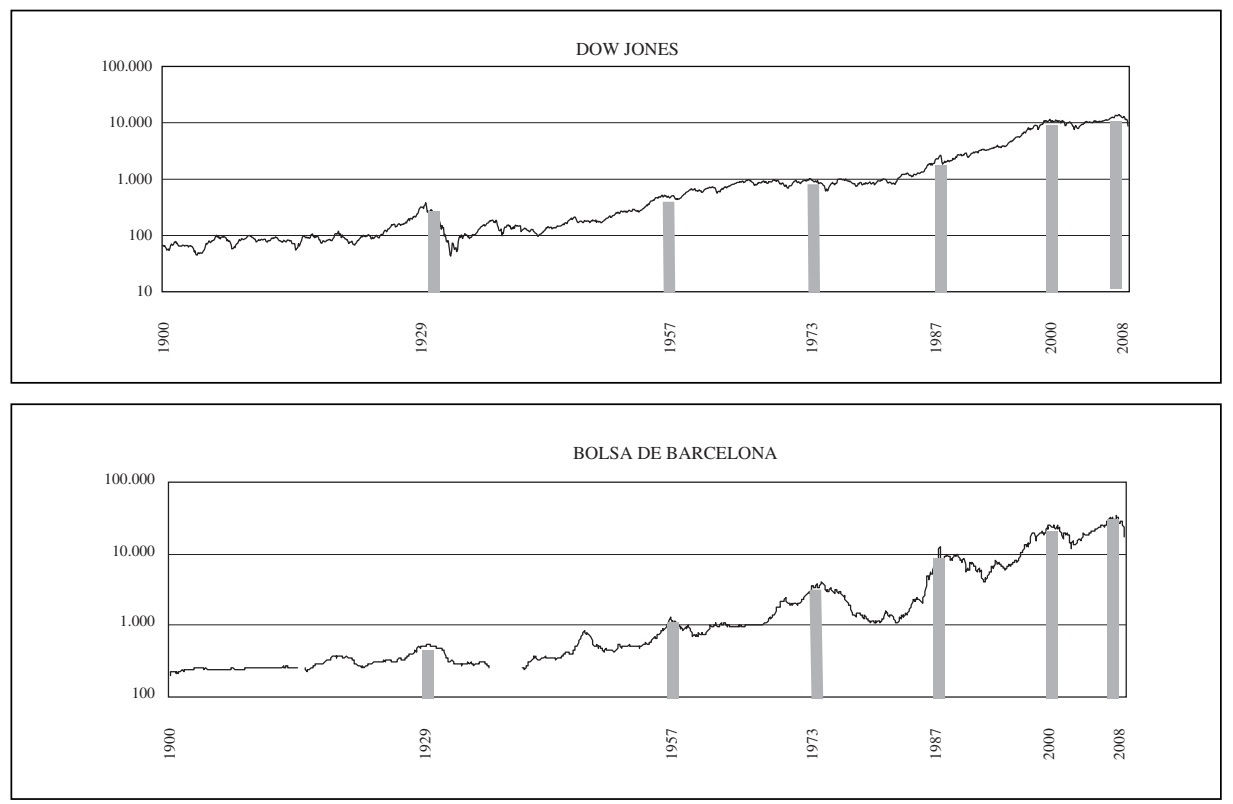


Se determina así la existencia de cinco ciclos entre 1929 y 2000. En términos generales, se evidencia la coincidencia temporal entre ambos mercados que aumenta progresivamente a partir de la globalización financiera. Los ciclos de referencia tienen sus puntos críticos en los años 1929, 1957, 1973, 1987 y 2000.

Respecto a la crisis de 1929, a parte consideraciones prolijas, existe una opinión mayoritaria en situar en el origen el boom inmobiliario de Florida y el sistema de pignoración automática de compras vigente entonces en Wall Street.
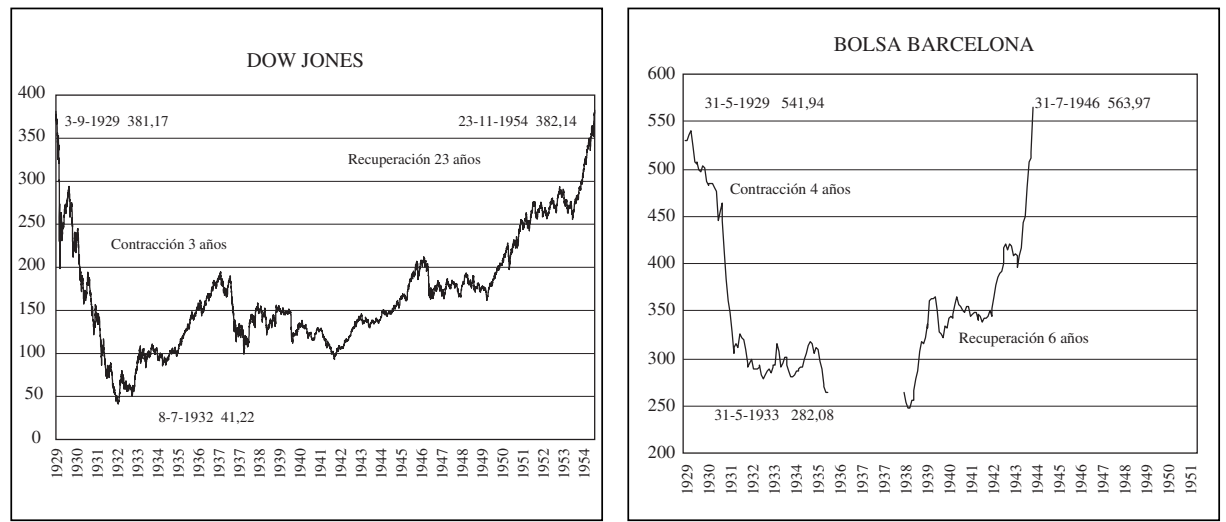

Los datos relevantes son los siguientes: a) la duración del ciclo fue aproximadamente de veintiséis años; b) la fase contractiva tuvo un alcance de alrededor de treinta y cuatro meses; c) la recuperación hasta los niveles máximos previos a la crisis fue de unos veintitrés años, y d) el crash se produjo en el mes de octubre del 29, con un porcentaje de caída del índice del 89\%.

La Guerra Civil distorsiona la situación en España. De todas maneras, la crisis se produce también en el mes de octubre de 1929, si bien con menor intensidad. El punto mínimo se registra en 1933, un año más tarde que en Wall Street. El descenso, desde el punto máximo es del 48\%, moviéndose luego el mercado transversalmente hasta el comienzo de la contienda. Terminada ésta, la bolsa reacciona a lo largo de una fase de recuperación de alrededor de unos seis años.

La crisis bursátil de 1957 tuvo, comparativamente mayor alcance en España que en EUA, como consecuencia de la penosa situación que había originado el largo período autárquico.

La bolsa cayó en el mes de enero, después de un discurso de Don Pedro Gual Villalví, nombrado Ministro sin cartera del nuevo gobierno. El profesor Estapé, tan sagaz como imaginativo, calificó a este colapso como crisis de «Gual Street». 
El descenso fue del $48 \%$, con una fase contractiva de unos treinta y cuatro meses y una larga recuperación, ya que los niveles de enero de 1957 no se alcanzaron hasta agosto de 1968. El ciclo, en concreto, tuvo una duración de once años.

Por su parte, la bolsa americana experimentó un relativo descenso inicial que, tras un rebrote equivalente, situó el índice a un menos $20 \%$, en el transcurso de una fase contractiva de escasamente dos años. El descenso fue fugaz y, en un marco más bien volátil, inició una rápida recuperación en el curso de un ciclo de algo más de tres años.
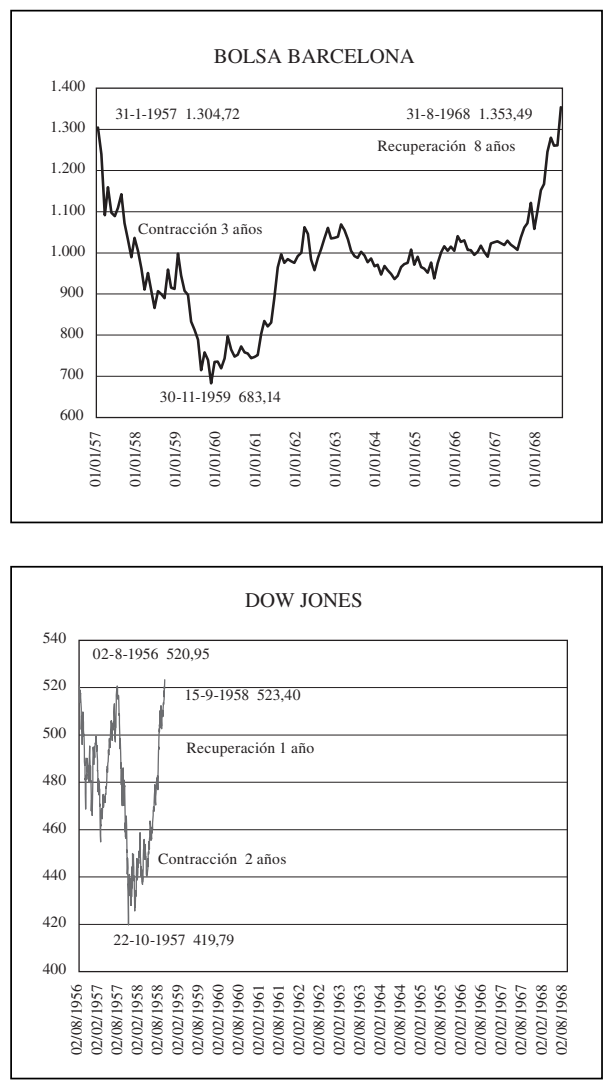

El tercer crash del siglo xx fue el de 1973, a raíz de la primera crisis del petróleo. En EUA la contracción fue importante y rápida. A lo largo de dos años el Dow Jones disminuyó un $45 \%$. Inició luego una recuperación en tramos a lo largo de los ocho años siguientes para alcanzar el máximo anterior. El ciclo tuvo una duración de diez años y las medidas de política económica puestas en vigor durante este período condicionaron de manera significativa los desarrollos bursátiles futuros, en particular en los sectores industriales y energético. 
En España la situación fue completamente diferente. El impacto inicial fue leve. El gobierno esgrimió su «tradicional amistad» con el mundo árabe, en el sentido de que aquí la subida del crudo tendría consecuencias escasas.
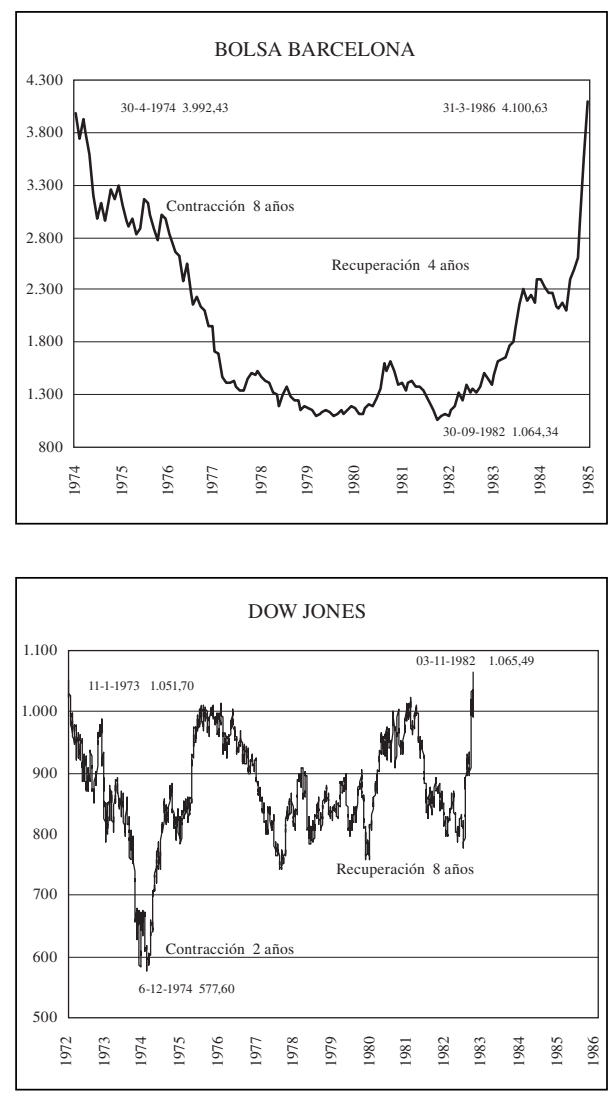

Sin embargo, la realidad fue muy diferente. La bolsa, se sumergió en un goteo constante y de fuerte intensidad y duración, sumando a la crisis del petróleo las vicisitudes que en el ámbito de la economía imprimió la transición política.

El descenso total fue del $73 \%$, con un ciclo de doce años de duración de los cuales ocho fueron de contracción.

El derrumbe de 1987 fue tan espectacular como inesperado. El sector bancario y en concreto la crisis de crédito se situaron como causas del cambio de tendencia. El giro se registra a finales de agosto de 1987 en el mercado americano y un mes más tarde alcanza la bolsa española. 
En Wall Street el descenso se produjo con rapidez inusitada. En tres meses el Dow Jones bajó un 32\%. El Índice General de la Bolsa de Barcelona, en cambio, muestra que la fase contractiva se extendió a lo largo de unos sesenta meses con una profundidad rayana al 68\%. Este contraste, contribuyó a que el ciclo español tuviera una duración cercana a los once años mientras que el americano se resolvió tan sólo en tres. Los cuadros siguientes grafican estos desarrollos.
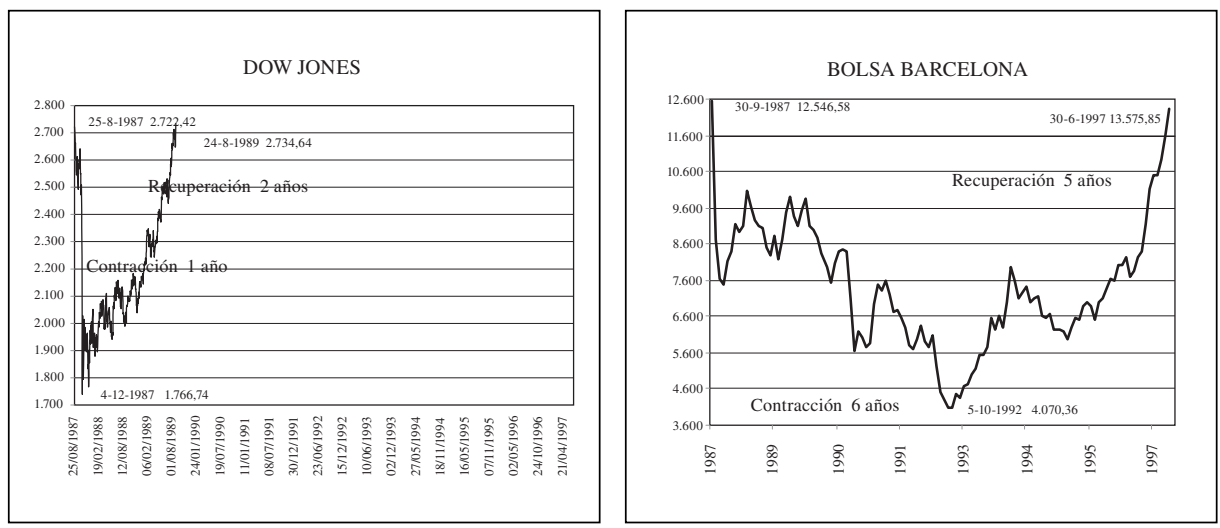

El pinchazo de la burbuja formada por el rápido y espectacular ascenso de las cotizaciones de empresas de nueva tecnología ocasionó la crisis punto com del año 2000.

En un marco globalizado, en donde la interrelación financiera es el exponente máximo de una tal mundialización, la dependencia cíclica se vio reforzada, particularmente en lo relativo a la duración de la amplitud de onda y de los períodos de descenso y recuperación.
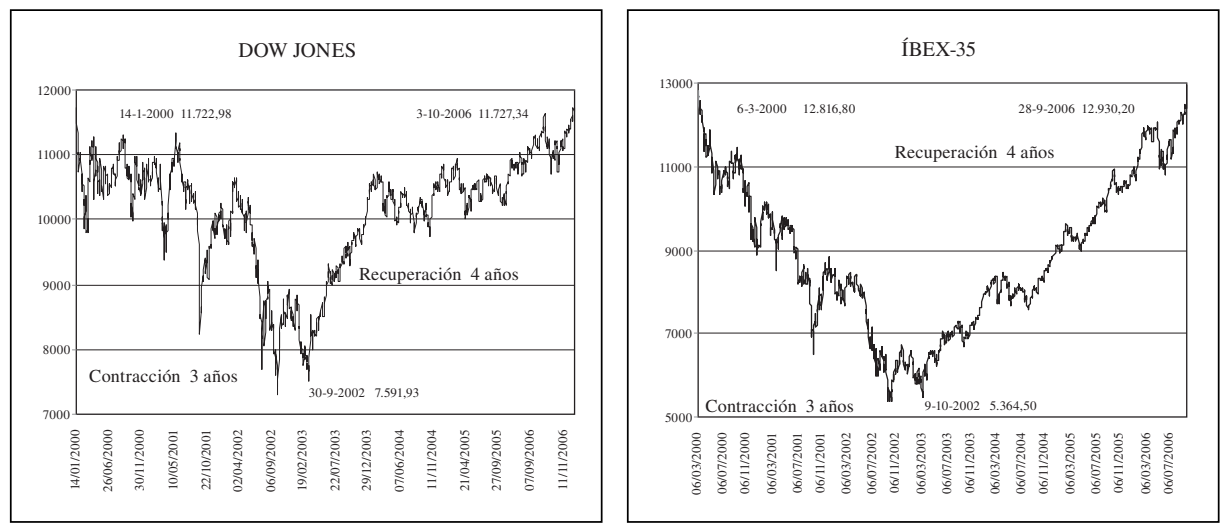
Tanto el Íbex como el Dow Jones registraron un ciclo temporal de siete años, con tres de contracción y cuatro de recuperación. Sin embargo, la profundidad fue muy diferente, pues mientras la bolsa americana descendió en su punto mínimo un 35\%, la española llegó hasta el $58 \%$.

\section{Conclusiones}

De las consideraciones anteriores, atendiendo a la crisis financiera $2008 \mathrm{y}$ de su repercusión en la economía real, caben remarcar los extremos siguientes:

Primero y a título anecdótico, el mes de octubre es la fecha fatídica por lo que atañe al desarrollo bursátil.

Segundo, el carácter de indicador avanzado del ciclo financiero respecto del ciclo real se cumple con mayor propiedad en la interrelación de fases contractivas.

Tercero, las crisis no explotan inicialmente en los mercados bursátiles sino que reflejan la caída de confianza originada por la aparición de desajustes en algún sector de la economía real.

Cuarto, ello no obstante, si el desajuste sectorial consolida efectivamente una crisis financiera, entonces la repercusión sobre la economía real es inevitable.

Quinto, como consecuencia de este doble proceso, resulta que si el desajuste sectorial concluye con una crisis bursátil sin otra repercusión, el ciclo tiene forma de $\mathbf{V}$. Por el contrario, si la crisis bursátil originada por el desajuste sectorial es el origen de una crisis financiera, el ciclo toma la forma de $\mathbf{U}, \mathbf{W}$ o $\mathbf{L}$.
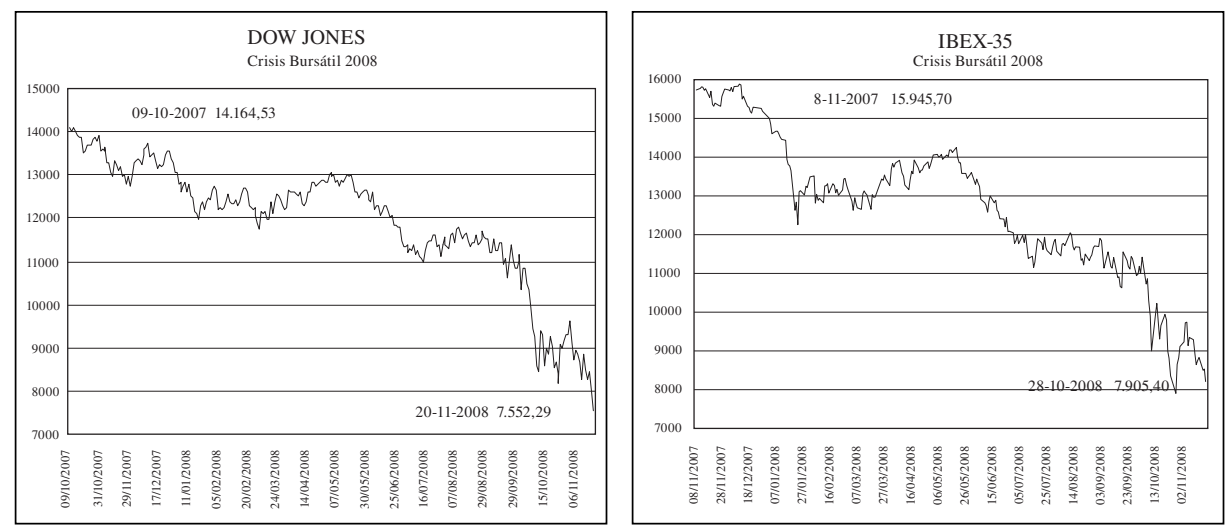
Sexto, habida cuenta el lapso temporal entre crisis no se observa con nitidez la ley de la inestabilidad financiera del modo que la formuló H. Minsky.

Séptimo, la interrelación cíclica internacional se hace más homogénea en el transcurso del tiempo, plausiblemente como consecuencia de la globalización financiera.

Octavo, cuanto mayor es la intensidad de la caída, más larga y menos volátil es la fase de recuperación, observándose, a la par, que cuanto más rápida es la fase contractiva mayor es la volatilidad en la recuperación.

Noveno, la duración de los ciclos tiende a reducirse, posiblemente por la mayor eficacia de las políticas anticíclicas. Sin embargo, la constatación afecta a las mediciones de tipo medio (ciclos comerciales o Juglar); no a las de larga duración (ciclos Kondratieff).

Décimo, en promedio, el descenso de los índices, de máximo a mínimo, se sitúa alrededor del 50\%. La duración de las fases contractiva y de recuperación, respectivamente, de 3-4 años y 8-7 años. Los ciclos son aproximadamente de 11 años.
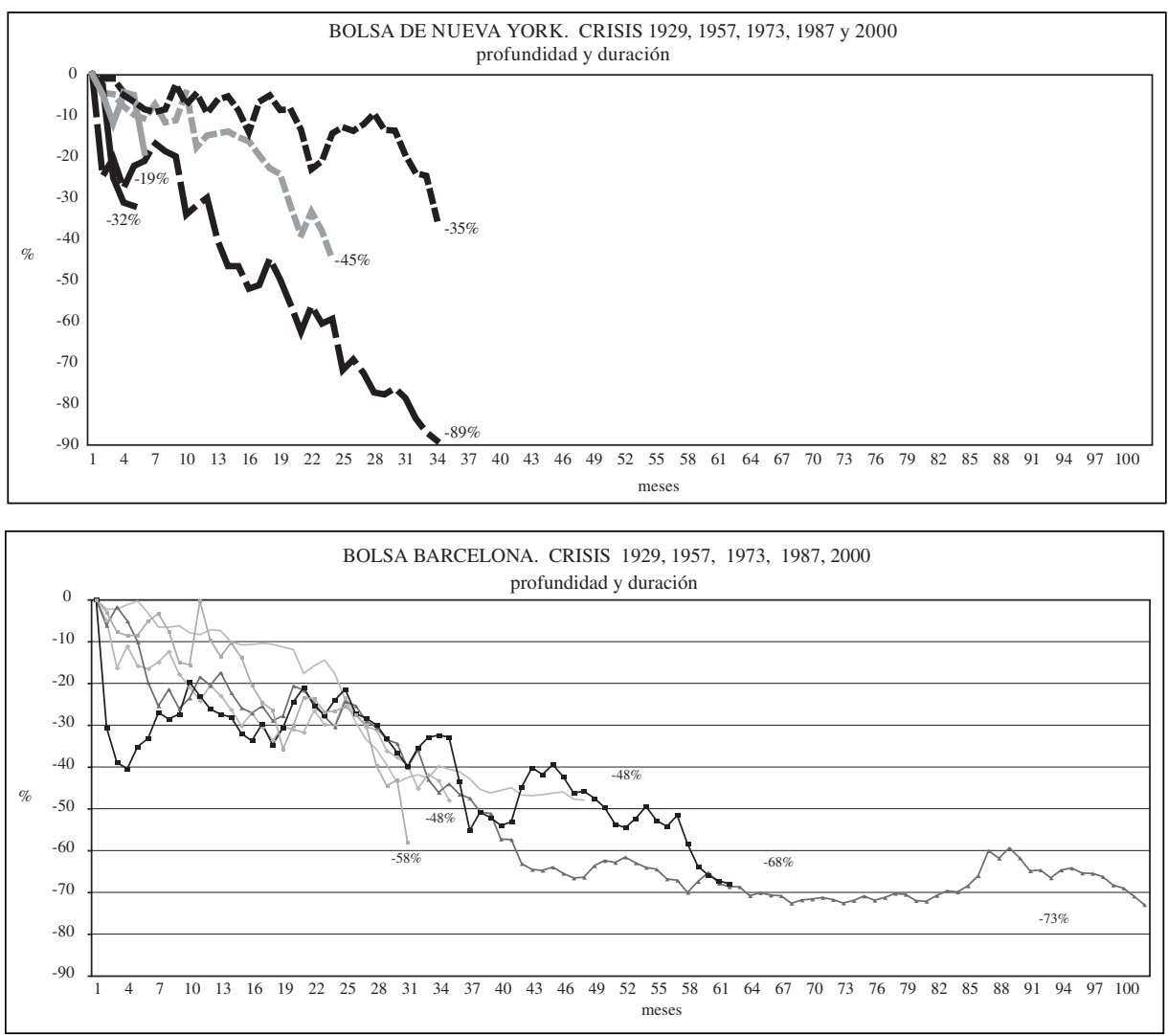
Undécimo, habitualmente los suelos se conforman después de retornar al nivel mínimo inicialmente alcanzado, en un lapso temporal de alrededor de 1,5 meses.

Duodécimo, comparativamente, los descensos son más profundos en el caso español que en el caso americano, la duración total del ciclo más larga, con fases contractivas también más largas y fases de recuperación de menor duración hasta reencontrar el máximo anterior.

La aplicación de estos resultados numéricos para estimar la profundidad y duración de la crisis financiera 2008 en el caso español deben ponderarse, cuando menos, por estos cinco factores de influencia: eficacia de la política anticíclica, posibilidad de operar al descubierto, préstamo de valores, práctica intra-day y volúmenes de contratación.

Las políticas estabilizadoras de mayor contraste tienen que ver con medidas monetarias, en particular, las relativas a la variación del tipo de interés.

$\mathrm{Su}$ incidencia en el mercado bursátil es proporcionalmente mayor en el caso americano que en el español. La eficacia de estas medidas, que aumenta relativamente con el paso del tiempo, se manifiesta de manera relevante en acortar las fases contractivas, alargar ocasionalmente los suelos y acentuar los movimientos de recuperación con volatilidades altas en los períodos iniciales.

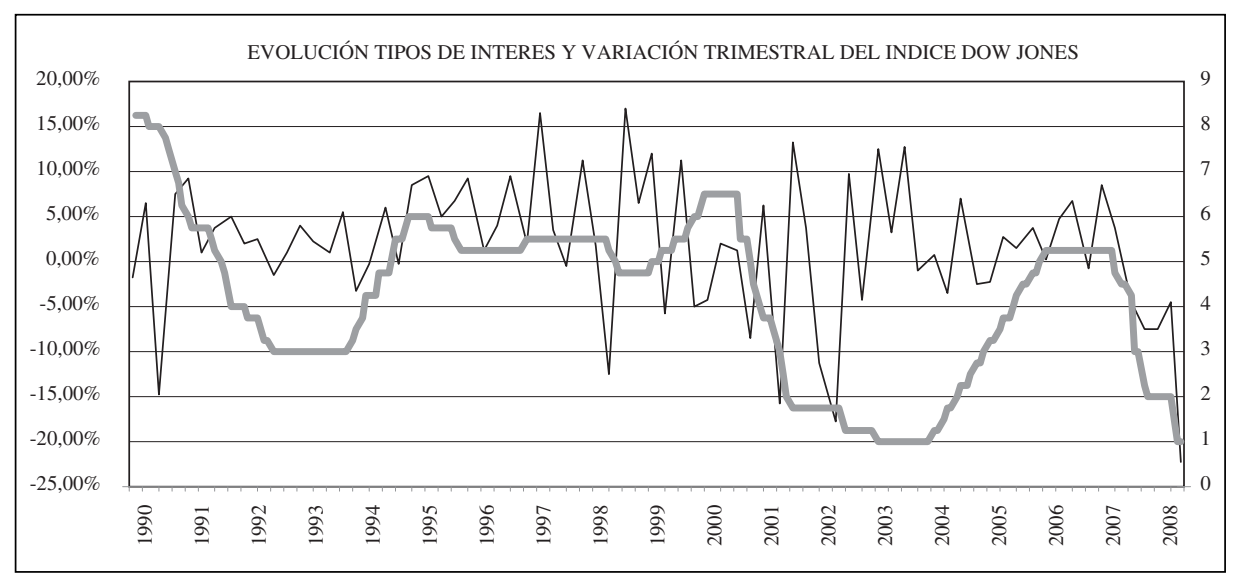

Ello no obstante, en los casos en que las políticas de tipos de interés no se anticipan a caídas repentinas, continuadas y profundas, sus efectos inmediatos restan relativizados por la concomitancia entre descensos de las cotizaciones y recortes de los tipos de interés. Esta concomitancia parece obedecer al hecho de que los inversores, ante la 
intensidad de la caída bursátil y la adopción de tales medidas correctoras, esperan que en el futuro próximo continuarán bajando los tipos de interés.

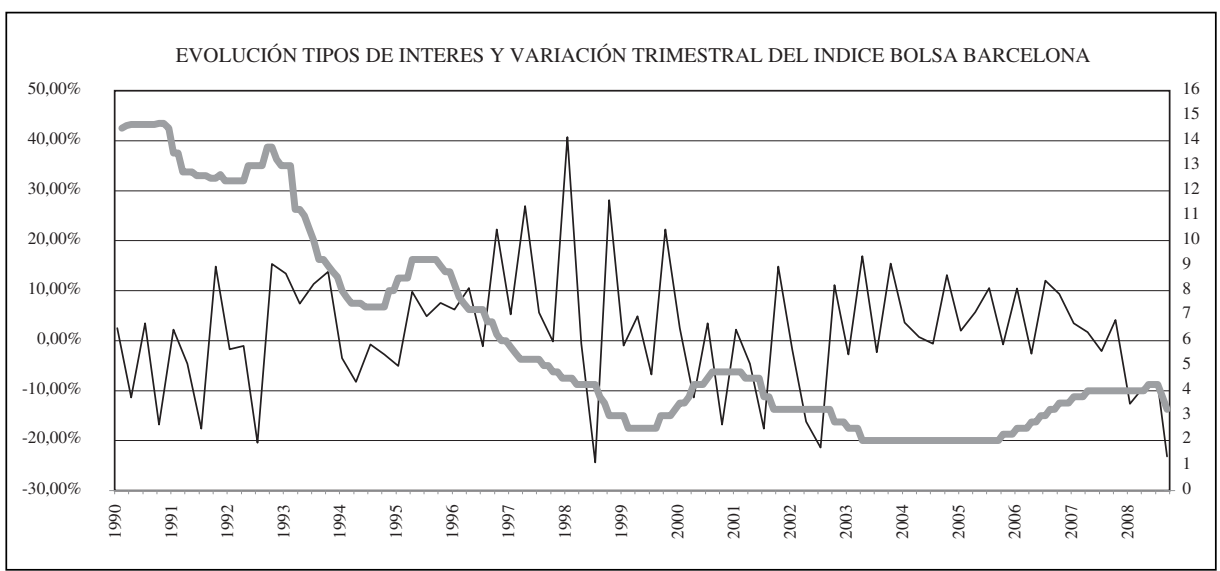

En segundo lugar, la operativa al descubierto tiene que ver con el mercado americano. Se trata de operaciones a corto puras, es decir, naked short sellings. Su influencia es perceptible en las fases contractivas acelerando la intensidad del descenso. En España este tipo de operación está prohibida y, en su caso, se penalizan los desajustes que surgen cuando la liquidación.

En el marco de las transacciones a crédito, en particular para el caso español, debe distinguirse entre préstamo de valores y operariones a crédito propiamente dichas. Tales prácticas han crecido a lo largo de los últimos años, en especial después de la crisis de la burbuja tecnológica del año 2000. También su incidencia es mayormente perceptible en los períodos bajistas.

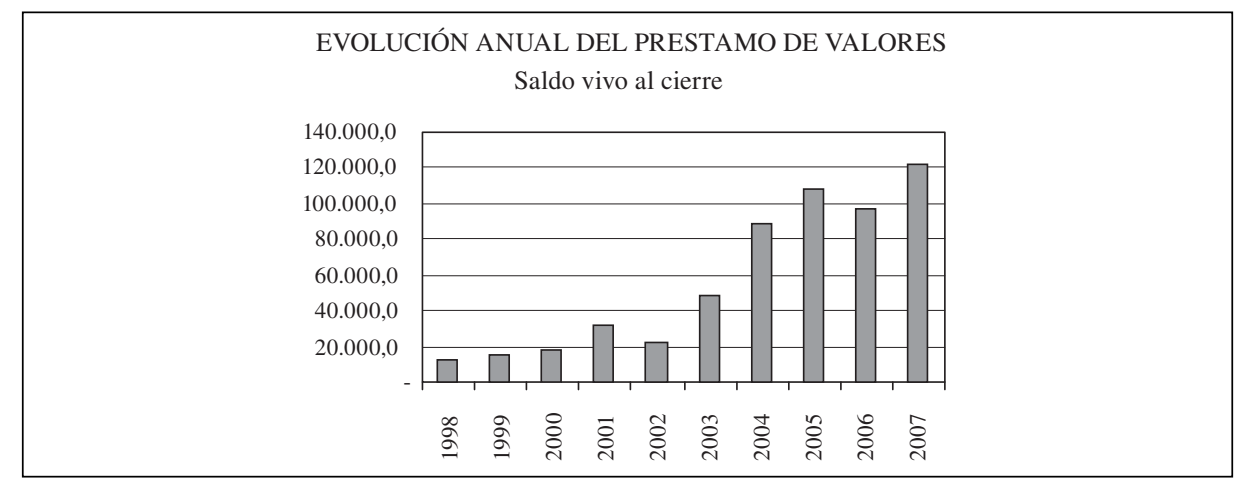


El cuarto factor a tener en cuenta es la práctica intra-day, tanto la que se realiza manualmente como la informatizada. En estos últimos años, este tipo de operativa ha crecido extraordinariamente en la bolsa española y su repercusión sobre el mercado afecta principalmente a los volúmenes de contratación.

De hecho, la evolución del volumen de contratación, en tanto que quinto factor a tener en cuenta, tiene importancia relevante para enmarcar sobre todo la duración del ciclo. La contratación, considerada en sí misma, sea posiblemente la característica más remarcable del cambio que ha experimentado la bolsa española desde mitad de los años noventa. Por ejemplo, hoy en día, en la Bolsa de Barcelona en treinta minutos se contrata la totalidad de lo contratado durante 1975.

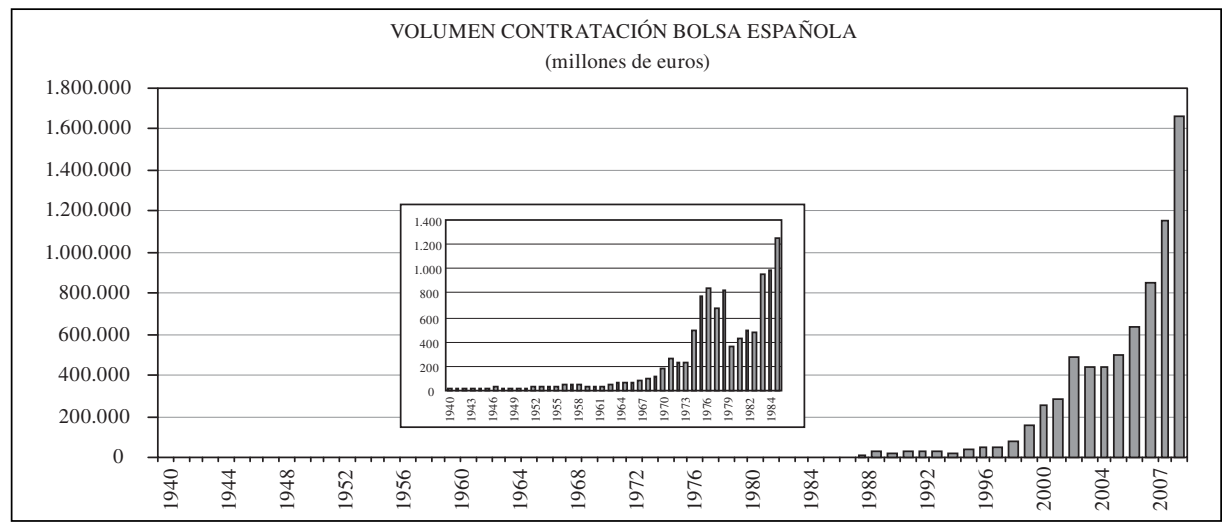

Este significativo cambio se debe a diferentes circunstancias. Primera, el desarrollo espectacular de la inversión colectiva, incluyendo los fondos de pensiones. Segunda, la importante reducción de los tipos de interés iniciada precisamente a mitad de los años 90. Tercera y mas laxamente, el incremento de la cultura financiera del público en general. En realidad, las conductas sujetas a la regla de las 3D's (diversificación, disponibilidad y duración) contribuyen tanto al aumento de la inversión en bolsa, como a la permanencia de los caudales invertidos, habida cuenta la percepción que es preferible minimizar el riesgo que maximizar el rendimiento.

Una cartera diversificada es requisito indispensable para esta finalidad. También coadyuvan en este sentido, tanto la conciencia de que los caudales invertidos en valores mobiliarios no deben precisarse para usos alternativos a corto plazo, como el sentimiento que una cartera identificada con la composición de los índices a largo plazo siempre sube. Lo primero, porque es conocido que los cierres diarios al alza y a la baja a lo largo de un ejercicio tienen igual probabilidad; lo segundo, porque la evidencia em- 
pírica muestra que el rendimiento bursátil en largos períodos de tiempo tiende a superar el coste de la vida (la bolsa española desde 1940 ha tenido en promedio un crecimiento anual nominal cercano al 9,5\%).

La reconsideración, pues, de los promedios históricos con estas matizaciones permite sostener, con todas las reservas que el caso requiere y que son muchas, que el actual ciclo bursátil que se inicia a mitad de 2007 va a tener una duración aproximada de 8-9 años (2007-2014/15).

La fase contractiva se extenderá posiblemente alrededor de 3 años (2007-2009), incluyendo la lateralidad del suelo determinado por una caída del $50 \%$ del registro máximo histórico de los 16.000 puntos.

La recuperación podría materializarse a lo largo de 5-6 años (2010-2014/15), con una volatilidad relativamente alta en el período inicial.

El suelo mínimo se estima en los 8.000 puntos de Íbex, con una franja de oscilación (desviación estándar) de $-0,50$ y $+0,70$.

\section{REFERENCIAS BIBLIOGRÁFICAS}

Berenguer, E., «Los derivados crediticios de tercera generación y su relación con la crisis hipotecaria del mercado subprime en EEUU», en Papers-Bolsa de Barcelona, septiembre 2007.

Estrella, A. y Mishkin, F. S., «Predicting U.S. Recessions: Financial Variables as Leading Indicators», en The Review of Economics and Statistics, febrero 1998.

HortalÀ, J., «Regularitats estadístiques i conducta borsària: la regla de les 3D's», en PapersBolsa de Barcelona, enero 2000.

— «La Bolsa de Barcelona 1830-2006», en Papers-Bolsa de Barcelona, octubre 2006.

PAn, J. y Singleton, K. J., «Default and Recovery Implicit in the Term Structure of Sovereign CDS Spreads», en The Journal of Finance, octubre 2008.

Siegel, J. J., Stocks for the Long Run, McGraw-Hill, 1998.

Torra, S. y Sierra, M. A., «Comportamiento probabilístico de la bolsa española: evidencia y aplicaciones», en Papers-Bolsa de Barcelona, diciembre 1998.

Viñolas, P.; Serrano, S. y Montesinos, M., «Sensibilidad de la bolsa a los tipos de interés», en Papers-Bolsa de Barcelona, agosto 1997. 